(2) Open Access Full Text Article

REVIEW

\title{
Nutrition support and dietary interventions for patients with lung cancer: current insights
}

\author{
This article was published in the following Dove Press journal: \\ Lung Cancer: Targets and Therapy \\ 27 January 2016 \\ Number of times this article has been viewed
}

\author{
Nicole Kiss ${ }^{1,2}$ \\ 'Nutrition and Speech Pathology \\ Department, Peter MacCallum Cancer \\ Centre, East Melbourne, VIC, Australia; \\ ${ }^{2}$ Department of Cancer Experiences \\ Research, Peter MacCallum Cancer \\ Centre, East Melbourne, VIC, Australia
}

\begin{abstract}
Malnutrition and weight loss are prevalent in patients with lung cancer. The impact of malnutrition on patients with cancer, and specifically in patients with lung cancer, has been demonstrated in a large number of studies. Malnutrition has been shown to negatively affect treatment completion, survival, quality of life, physical function, and health care costs. Emerging evidence is providing some insight into which lung cancer patients are at higher nutritional risk. In lung cancer patients treated with radiotherapy, stage III or more disease, treatment with concurrent chemotherapy and the extent of radiotherapy delivered to the esophagus appear to confer a higher risk of weight loss during and post-treatment. Studies investigating nutrition interventions for lung cancer patients have examined intensive dietary counseling, supplementation with fish oils, and interdisciplinary models of nutrition and exercise interventions and show promise for improved outcomes from these interventions. However, further research utilizing these interventions in large clinical trials is required to definitively establish effective interventions in this patient group.
\end{abstract}

Keywords: lung cancer, nutrition, malnutrition

\section{Introduction}

Lung cancer is the most common cancer worldwide with an estimated global incidence in 2012 of 1.8 million new cases, representing $12.9 \%$ of all new cancers. ${ }^{1}$ Treatment for lung cancer may consist of surgery, chemotherapy or radiotherapy, or any combination of these modalities. The treatment modality or combination depends on the prognostic indicators of performance status, weight loss, and stage of disease. However, other factors such as age and medical comorbidities are also taken into consideration. ${ }^{2,3}$ This review will discuss nutrition impact symptoms associated with lung cancer and its treatment, factors associated with malnutrition in lung cancer and the impact on treatment and patient outcomes, as well as review nutrition interventions used with lung cancer patients.

\section{Symptoms that impact on nutrition}

A systematic review of symptoms in adults with lung cancer found that fatigue, pain, loss of appetite, coughing, and insomnia were the most common symptoms patients presented with at diagnosis. ${ }^{4}$ In contrast, the most common symptoms experienced during chemotherapy treatment were nausea, vomiting, and hair loss, and during radiotherapy treatment were dysphagia and sore throat. ${ }^{4}$ Clinical practice guidelines for the prevention, diagnosis, and management of lung cancer patients report that anorexia, fatigue, and esophagitis are the acute toxicities associated
Correspondence: Nicole Kiss Nutrition and Speech Pathology Department, Locked Bag I, A'Beckett Street, East Melbourne, VIC 3002, Australia

Tel +6I 396561002

Fax +6I 39656 I402

Email nicole.kiss@petermac.org submit your manuscript | www.dovepress.com

Dovepress

http://dx.doi.org// 0.21 47/LCTT.S85347
Lung Cancer: Targets and Therapy 2016:7 I-9 I

(c) (i) (-) 2016 Kiss. This work is published and licensed by Dove Medical Press Limited. The full terms of this license are available at https://www.dovepress.com/terms.php and incorporate the Creative Commons Attribution - Non Commercial (unported, v3.0) License (http:///creativecommons.org/licenses/by-nc/3.0). By accessing the work you for commercial use of this work, please see paragraphs 4.2 and 5 of our Terms (https://www.dovepress.com/terms.php). 
with thoracic radiotherapy. ${ }^{5}$ An acute toxicity scoring tool developed for use in patients being treated with radiotherapy for lung cancer includes dysphagia, nausea, vomiting, skin reactions, and fatigue as the side effects that should be assessed and monitored during treatment. ${ }^{6}$ Patients with lung cancer have been reported to experience more symptoms than patients with other cancer diagnoses, with the type and number of symptoms varying over the course of the illness trajectory. ${ }^{4}$ A recent cross-sectional study of 450 patients with advanced stage non-small cell lung cancer (NSCLC) found $100 \%$ of patients experienced fatigue and $97 \%$ experienced loss of appetite. ${ }^{7}$

Nutrition impact symptoms are symptoms which affect the ability to achieve adequate nutritional intake and increase the risk of developing malnutrition. ${ }^{8}$ Segura et al, found in their malnutrition prevalence study that the presence of two nutrition impact symptoms were associated with difficulties in food intake. ${ }^{9}$ A number of the symptoms and treatment toxicities reported to be experienced by patients with lung cancer include nutrition impact symptoms, specifically loss of appetite, nausea, vomiting, fatigue, dysphagia, and esophagitis, placing lung cancer patients at increased risk of malnutrition.

\section{Prevalence of malnutrition in lung cancer}

Oncology patients are one of the groups with the highest prevalence of malnutrition. ${ }^{10}$ In a cross-sectional survey of 3,122 adult patients in acute care wards, patients admitted to oncology wards were 1.7 times more likely to be malnourished than other participants. ${ }^{11}$ Malnutrition rates in patients with lung cancer are particularly high (Table 1). In a prospective longitudinal study of the prevalence of malnutrition in patients presenting to an Australian oncology clinic prior to chemotherapy or radiotherapy treatment, $69 \%$ of patients with lung cancer were malnourished, higher than patients with colorectal or head and neck cancer, $57 \%$ and $45 \%$ respectively. ${ }^{12}$ Several other studies have confirmed high rates of malnutrition or significant weight loss in patients with lung cancer. Hébuterne et al, found an overall rate of $45 \%$ malnutrition in inpatients with lung cancer. In the same study, a sub-analysis found $73 \%$ of lung cancer patients with metastatic disease were malnourished compared to $5 \%$ of those with localized disease. ${ }^{13}$ Using the patient generated subjective global assessment, a nutrition assessment tool, Segura et al, found that $56 \%$ of lung cancer patients with advanced stage disease had a score greater than nine, indicating a critical need for nutrition intervention. ${ }^{9}$ In a group of oncology patients presenting to European outpatient clinics the median weight loss among lung cancer patients was $6.5 \%$, with $34.5 \%$ reporting significant weight loss of more than $10 \%{ }^{14}$ A prospective study designed to evaluate the nutritional status of 207 patients referred to an outpatient radiotherapy department demonstrated that $33 \%$ of lung cancer patients were malnourished prior to starting radiotherapy, increasing to $50 \%$ at the end of treatment. ${ }^{15}$ More recent studies in lung cancer patients receiving radiotherapy have found between $22 \%$ to $31 \%$ of patients have $5 \%$ or more weight loss within 90 days from the start of radiotherapy, with the median weight loss among these patients between $8 \%$ to $9 \% .^{16,17}$

Table I Malnutrition point prevalence studies in oncology patients reporting malnutrition rates in lung cancer subgroups

\begin{tabular}{|c|c|c|c|c|}
\hline Citation & Population & Setting & $\begin{array}{l}\text { Malnutrition assessment } \\
\text { method }\end{array}$ & $\begin{array}{l}\text { Prevalence in } \\
\text { lung patients }\end{array}$ \\
\hline $\begin{array}{l}\text { Mariani } \\
\text { et al }{ }^{14}\end{array}$ & $\begin{array}{l}\text { Adult cancer outpatients at } \\
\text { diagnosis or in various stages of } \\
\text { treatment or follow-up, } \mathrm{N}=1,556 \\
\mathrm{n}=229 \text { (lung) }\end{array}$ & $\begin{array}{l}\text { Outpatient cancer } \\
\text { patients of } 17 \text { hospitals, } \\
\text { universities or scientific } \\
\text { institutions in Italy }\end{array}$ & $\begin{array}{l}\text { Weight loss }>10 \% \text { of usual body } \\
\text { weight }\end{array}$ & $34.5 \%$ \\
\hline $\begin{array}{l}\text { Hébuterne } \\
\text { et al }{ }^{13}\end{array}$ & $\begin{array}{l}\text { Adult cancer inpatients, } \mathrm{N}=1,903 \\
\mathrm{n}=247 \text { (lung) }\end{array}$ & $\begin{array}{l}\text { Inpatient wards of } \\
\text { I } 54 \text { public or private } \\
\text { hospitals in France }\end{array}$ & $\begin{array}{l}\text { BMI } \leq 18.5 \mathrm{~kg} / \mathrm{m}^{2} \text { (for aged I8-74) } \\
\text { or BMI } \leq 2 \mathrm{I} \mathrm{kg} / \mathrm{m}^{2} \text { (for patients } \\
\text { aged over } 75 \text { ) and } / \text { or } \leq 10 \% \text { loss of } \\
\text { weight from beginning of disease }\end{array}$ & $45 \%$ \\
\hline $\begin{array}{l}\text { Segura } \\
\text { et } \mathrm{al}^{9}\end{array}$ & $\begin{array}{l}\text { Adult patients with advanced cancer } \\
\text { at diagnosis or in various stages of } \\
\text { treatment or follow-up, } \mathrm{N}=78 \mathrm{I} \\
\mathrm{n}=\mid 72 \text { (lung) }\end{array}$ & $\begin{array}{l}\text { Inpatient, outpatient or } \\
\text { home-based care patients } \\
\text { within the Spanish } \\
\text { National Health System }\end{array}$ & $\begin{array}{l}\text { Patient generated subjective global } \\
\text { assessment }(\mathrm{PG}-\mathrm{SGA}) \text { score }>9\end{array}$ & $56.4 \%$ \\
\hline $\begin{array}{l}\text { Read } \\
\text { et } \mathrm{al}^{12}\end{array}$ & $\begin{array}{l}\text { Adult cancer patients at } \\
\text { first presentation, prior to } \\
\text { chemotherapy, } \mathrm{N}=|4| \\
\mathrm{n}=32 \text { (lung) }\end{array}$ & $\begin{array}{l}\text { Outpatient oncology } \\
\text { clinic in two hospitals in } \\
\text { Sydney (Australia) }\end{array}$ & PG-SGA category B or C & $69 \%$ \\
\hline
\end{tabular}

Abbreviations: BMI, body mass index; PG-SGA, patient-generated subjective global assessment. 
Importantly, approximately half of these patients reached this degree of weight loss during the post-treatment period, between 3 to 6 weeks following completion of radiotherapy, highlighting the post-treatment period as an important time to be monitoring nutrition. These studies demonstrate that malnutrition is prevalent across the disease and treatment trajectory of patients with lung cancer.

\section{Factors associated with weight loss}

In clinical practice it is useful to understand any factors present at diagnosis or during treatment that are associated with a higher risk of weight loss or developing malnutrition. This allows clinicians to ensure patients with a high risk diagnosis or a high risk treatment are identified and provided with appropriate support. In patients with head and neck cancer these factors are relatively well-known. Evidence based practice guidelines for the nutritional management of adults with head and neck cancer recommend that patients with T4 or hypopharyngeal tumors undergoing concurrent chemoradiotherapy should be considered for prophylactic placement of a percutaneous endoscopic gastrostomy tube due to the risk of weight loss and malnutrition associated with these diagnoses and treatment. ${ }^{18}$ The literature also suggests that all T3 and T4 head and neck tumors, ${ }^{19,20}$ all stages of tumors of the hypopharynx, oral cavity, oropharynx, and larynx, ${ }^{21}$ high doses of radiotherapy to the pharyngeal constrictor muscles, ${ }^{22}$ nodal stage, ${ }^{23}$ combined chemoradiotherapy, ${ }^{24-26}$ and pre-treatment weight $\operatorname{loss}^{26,27}$ are associated with weight loss, but the evidence for these factors is less consistent across studies. Factors associated with weight loss and malnutrition in patients with lung cancer are just beginning to become established.

A number of studies have investigated clinical and radiotherapy dosimetric factors associated with the development of acute or late radiation-induced esophagitis in lung cancer patients. ${ }^{28-30}$ A systematic review of dose-volume parameters predictive of esophagitis in patients receiving thoracic radiotherapy found the parameters that were most consistently and strongly associated with development of esophagitis were mean esophageal dose, and the volume of the esophagus receiving a dose of $20 \mathrm{~Gy}, 30 \mathrm{~Gy}, 40 \mathrm{~Gy}$, $50 \mathrm{~Gy}$, and $60 \mathrm{~Gy} .{ }^{31} \mathrm{~A}$ more recent systematic review and meta-analysis investigated factors predictive of clinically significant radiation-induced esophagitis in 1,082 patients from 15 studies conducted in Europe, North America, Asia, and Australia. It was identified that, while on univariate analysis several factors are predictive of radiation-induced esophagitis including disease stage, $\mathrm{N}$ stage, poor performance status, and type of concurrent chemotherapy, on multivariate analysis the volume of the esophagus receiving $60 \mathrm{~Gy}$ alone emerged as the best predictor. ${ }^{32}$

Two recent studies have investigated factors associated with clinically significant weight loss in lung cancer patients receiving radiotherapy. In a retrospective cohort of 96 lung cancer patients treated with radiotherapy with or without concurrent chemotherapy $31 \%(n=30)$ of patients had clinically significant weight loss of $5 \%$ or greater within the 90 days from commencement of radiotherapy. The factors determined to be associated with $\geq 5 \%$ weight loss were treatment with concurrent chemotherapy for both small cell lung cancer (SCLC) and NSCLC, and late stage disease in NSCLC only. ${ }^{16}$ A second study of 50 NSCLC patients treated with concurrent chemo-radiotherapy investigated radiotherapy dosimetric factors associated with $\geq 5 \%$ weight loss. Similar to the literature reporting associations between dosimetric factors and esophagitis, an association was found between clinically significant weight loss and the maximum dose to the esophagus, and the absolute esophageal length receiving doses of 40 Gy, 50 Gy, and 60 Gy. ${ }^{17}$ These studies have provided new insight into the lung cancer patients who are at higher risk of nutritional decline during radiotherapy treatment (Table 2).

\section{Impact of weight loss and malnutrition}

It is well established that malnutrition and weight loss have significant negative consequences on both patient centered and treatment outcomes. Multiple international evidencebased guidelines contain statements regarding the negative impact of malnutrition on quality of life (QoL), functional status, survival, hospital length of stay, and health care costs. ${ }^{33-35}$ There are relatively few studies that have investigated the impact of malnutrition specifically in patients with lung cancer, however, many studies have been undertaken in mixed cancer populations and therefore have direct relevance to lung cancer patients.

Table 2 Factors associated with higher nutritional risk in lung cancer patients receiving radiotherapy

\begin{tabular}{ll}
\hline $\begin{array}{l}\text { Associations with clinically } \\
\text { significant weight loss } \geq \mathbf{5 \%}\end{array}$ & $\begin{array}{l}\text { Associations with acute } \\
\text { radiation-induced esophagitis }\end{array}$ \\
\hline - Concurrent chemotherapy & - Mean esophageal dose \\
- Disease stage III or more & - Volume of the esophagus \\
- Maximum radiotherapy dose to & $\begin{array}{l}\text { receiving } 20,30,40,50, \text { and } \\
\text { the esophagus }\end{array}$ \\
$\begin{array}{l}\text { - Absolute esophageal length } \\
\text { receiving doses of } 40,50 \text {, and } 60 \mathrm{~Gy}\end{array}$ \\
\hline
\end{tabular}




\section{Patient centered outcomes}

Studies in mixed tumor groups which included lung cancer patients have demonstrated the impact of weight loss on QoL, finding significantly worse QoL in patients with weight loss. ${ }^{36,37}$ In 104 lung, breast, and ovarian cancer patients, Ovesen et al, found QoL prior to any treatment was rated worse in patients who had experienced more than $5 \%$ loss of weight over the previous 3 months $(P<0.05) .{ }^{37}$ In a mixed group of 907 cancer patients Nourissat et al, found similar results by comparing patients with and without $10 \%$ loss of weight since the onset of their illness, and at varying stages of treatment. The authors found mean global QoL was significantly poorer $(P<0.001)$ in patients with weight loss. ${ }^{36}$ A number of studies investigating QoL have also looked at associations between weight loss or malnutrition and functional capacity using the functional sub-scales of the QoL questionnaires. The only one that included a large number of lung cancer patients $(n=138)$ was the study by Nourissat et al. ${ }^{36}$ In this study, patients with greater than $10 \%$ weight loss had worse outcomes on the European Organization for Research and Treatment of Cancer Quality of Life Questionnaire (EORTC-C30) functional scales; physical functions $(P<0.001)$; functional handicap $(P<0.001)$; emotional functions $(P=0.004)$; cognitive functions $(P<0.001)$, and social functions $(P<0.001)$. Similar results have been observed in studies of head and neck cancer, gastrointestinal cancer, and mixed cancer populations..$^{38-41}$

Patients with poor nutritional status may be more likely to develop treatment toxicities which can result in a reduced dose of treatment being delivered. ${ }^{42,43}$ The development of treatment toxicities in patients with and without malnutrition or weight loss has also been studied using the symptom scales within QoL questionnaires. In addition, some studies have used toxicity scoring tools to determine differences. The results of studies investigating the impact of weight loss or malnutrition on treatment toxicities are less consistent than those for QoL and functional capacity. This may be due to the large range of toxicities that are assessed and the different methods used to assess them. Four such studies have been conducted in patients with lung cancer. Ross et al, assessed toxicity using the World Health Organization toxicity criteria in lung cancer patients undergoing chemotherapy treatment with and without $10 \%$ weight loss. ${ }^{44}$ NSCLC patients with weight loss were significantly more likely to develop severe anemia $(P=0.003)$ but this finding was not observed in SCLC or patients with mesothelioma. No differences were observed for any other toxicities. In a study of NSCLC patients undergoing chemotherapy, treatment toxicities were assessed using the National Cancer Institute Common Toxicity Criteria for Adverse Events. ${ }^{45}$ When all toxicities were assessed, patients who were malnourished developed more toxicities than well-nourished patients ( 31 vs $22, P=0.02$ ). In the study by Nourissat et al, described previously, all symptoms except insomnia in the EORTC-C30 symptom scale were significantly worse for patients with greater than $10 \%$ weight loss. ${ }^{36} \mathrm{~A}$ retrospective study of 425 stage IIIB NSCLC patients receiving chemoradiotherapy found that patients who lost weight during treatment experienced significantly more grade 3 hematological and non-hematological toxicities, including acute radiation-induced esophagitis, than patients who maintained or gained weight. In addition, the onset of acute radiation-induced esophagitis was significantly earlier (day 16 vs day 23 of radiotherapy, $P=0.02$ ) in weight losing patients. ${ }^{46}$

Numerous studies using the EORTC-C30 as a measure of QoL include a separate analysis of the fatigue symptom scale from this questionnaire. The results of these studies overwhelmingly support an association between fatigue and weight loss or malnutrition. Six of these studies, in head and neck or mixed cancer groups, report significantly worse fatigue in patients with weight $\operatorname{loss}^{36,38,39,41,47}$ or malnutrition. ${ }^{40}$ In the study by Nourissat et al, mean fatigue score in patients with less than $10 \%$ weight loss was 36.6 compared to 55.4 in patients with greater than $10 \%$ weight loss $(P<0.001)$.

The use of health care resources is an important outcome measure in the setting of rising health care costs and an aging population. Studies in cancer patients including heath care utilization as an outcome measure have usually focused on hospital admissions and length of stay. There is strong evidence that malnutrition affects health care utilization and costs. Only one study has investigated health care utilization specifically in lung cancer patients. The retrospective study by Topkan et al, of 425 stage IIIB NSCLC patients demonstrated a higher rate of hospitalization ( $11.3 \%$ vs $6.4 \%, P=0.01)$ in patients who lost weight during chemoradiotherapy compared to those who maintained or gained weight. ${ }^{46}$

\section{Treatment outcomes}

A number of studies across multiple cancer types have found associations between weight loss or malnutrition and poorer treatment outcomes. These associations were independent of disease stage and other known prognostic factors. ${ }^{43,44,48,49}$ The mechanism by which this might occur is not fully understood but it is suggested that patients with weight loss or malnutrition may have a poorer immune response, and poorer lung and cardiac function. ${ }^{42,44}$ 
A number of studies have shown a reduced ability to complete cancer treatment among malnourished patients. A retrospective cohort of lung cancer patients $(n=780)$ undergoing chemotherapy treatment found less patients who had presented with weight loss completed three cycles of chemotherapy than those who presented without weight loss $(67 \%$ vs $81 \%, P<0.001) .{ }^{44}$ When patients with NSCLC, SCLC, and mesothelioma were examined separately, this finding was confirmed in NSCLC patients $(64 \%$ vs $78 \%$, $P=0.003$ ) but not SCLC patients ( $77 \%$ vs $84 \%, P=0.1)$ or mesothelioma patients ( $53 \%$ vs $72 \%, P=0.05)$. When the authors looked at frequency of dose reductions or treatment delays between patients with and without weight loss no significant difference was found overall. However, more patients with weight loss experienced treatment delays in the sub-group with NSCLC ( $9 \%$ vs $4 \%, P=0.04$ ). Similarly, in a study by Topkan et al, patients who lost weight were less able to tolerate full concurrent chemoradiotherapy treatment. While both weight losing and weight stable patients all completed the prescribed radiotherapy dose, more patients who lost weight required a chemotherapy dose reduction $(23 \% \mathrm{vs}$ $11 \%, P=0.02$ ) or cessation of the chemotherapy component of treatment ( $17 \%$ vs $6.9 \%, P=0.007) .{ }^{46}$ Studies in other patient groups show similar findings..$^{50,51}$

In a study of lung cancer patients undergoing chemotherapy, Ross et al, assessed both objective response to treatment on computed tomography scan and symptomatic response to treatment defined as improvement in a symptom maintained for a minimum of 3 weeks. ${ }^{44}$ No significant difference was found between patients with and without weight loss in objective response to treatment for either NSCLC or SCLC, however, a trend toward a lower response rate was observed in mesothelioma patients with weight loss $(P=0.05)$. In contrast, NSCLC and mesothelioma patients with weight loss had fewer symptomatic responses compared to those without weight loss ( $44 \%$ vs $60 \%, P=0.004 ; 33 \%$ vs $65 \%$, $P=0.03$, respectively). However, there was no difference in symptomatic response in SCLC ( $52 \%$ vs $64 \%, P=0.06$ ). Again, studies in other patient groups demonstrate similar findings. ${ }^{42,49}$

A landmark study by Dewys et al, established the prognostic effect of weight loss, independent of performance status or extent of the tumor, in cancer patients undergoing 12 different chemotherapy protocols. ${ }^{43}$ This was a large study of multiple tumor groups $(n=3,047)$, which demonstrated across all 12 protocols that patients with weight loss had reduced survival with this difference being significant in nine of the 12 protocols. In the protocols treating SCLC and
NSCLC, median survival was shorter in patients with weight loss compared to those without weight loss ( 27 vs 34 weeks, $P<0.05 ; 14$ vs 20 weeks, $P<0.01$, respectively). In addition there appeared to be a difference in median survival by degree of weight loss in the NSCLC protocol (17 weeks $0 \%-5 \%$; 13 weeks $5 \%-10 \% ; 11$ weeks $0>10 \%, P<0.01)$. Ross et al, also determined weight loss to be an independent predictor of shorter overall survival in NSCLC (relative risk $[R R]=1.33$, $P=0.009)$, SCLC (RR $=1.5, P=0.003)$, and mesothelioma $(\mathrm{RR}=1.92, P=0.03)$ patients undergoing chemotherapy treatment. ${ }^{44}$ These results are further supported by a study in stage III lung cancer patients undergoing chemoradiotherapy followed by surgery. ${ }^{52}$ Patients who experienced greater than $5 \%$ weight loss during chemoradiotherapy had a shorter overall survival (hazard ratio $[\mathrm{HR}] 2.80, P=0.03$ ). In the same study, patients who had a body mass index greater than 25 prior to treatment but lost greater than 5\% weight during chemoradiation, had a shorter overall and progression-free survival (HR 4.63, $P=0.005$; HR 6.03, $P=0.007$, respectively). Also in radiotherapy patients, Topkan et al, found better overall survival, progression-free survival, and distant metastasis free survival (all $P<0.05$ ) in stage IIIB NSCLC patients who maintained or gained weight during chemoradiotherapy compared to those who lost weight. ${ }^{46}$ In surgical lung cancer patients, impaired nutritional status appears to be associated with reduced long-term survival but not mortality in hospital following surgery. Studies have reported an independent association between nutritional impairment measured by body mass index, fat free mass index or weight loss and reduced long-term survival, ${ }^{53,54}$ but failed to find an association between nutritional parameters and 30-day in-hospital mortality in surgical lung cancer patients. ${ }^{55}$

With a high prevalence of malnutrition among lung cancer patients and in the setting of strong evidence demonstrating poorer outcomes for malnourished patients, it is important to examine the most effective type of nutrition intervention to prevent or treat malnutrition in this population.

\section{Nutrition interventions}

Early research conducted during the 1980s on nutrition intervention in lung cancer focused on the effect of parenteral nutrition during chemotherapy and radiotherapy on treatment outcomes and survival with mixed results. ${ }^{56-58}$ Several of these randomized controlled trials were underpowered to detect an effect. ${ }^{59}$ It is now standard clinical practice to reserve the use of parenteral nutrition for those patients with a non-functioning gastrointestinal tract, ${ }^{60}$ and therefore the results of these studies are now of limited interest. 
More recent studies have focused on the effect of novel agents, such as omega-3 fatty acids, or dietary counseling in lung cancer patients.

\section{Dietary counseling}

Intensive, individualized dietary counseling or medical nutrition therapy is the intervention which has been demonstrated to improve dietary intake, nutritional status, functional status, and QoL in head and neck and gastrointestinal cancer patients treated with radiotherapy. ${ }^{18,35,61}$ However, there have been limited high quality studies undertaken investigating this intervention in patients with lung cancer. A recent systematic review on nutrition interventions in lung cancer patients treated with radiotherapy and/or chemotherapy revealed only five studies have investigated either dietary counseling or oral supplements in this patient group over the past 30 years. ${ }^{62}$ The systematic review found that simple dietary counseling improved energy and protein intake in lung cancer patients receiving chemotherapy but appeared to have no impact on other outcomes including weight, nutritional status, QoL, treatment response or survival. However, the studies in chemotherapy patients all had substantial limitations which may have precluded the ability to detect an impact on these outcomes. There was insufficient evidence found investigating dietary counseling or oral supplements in lung cancer patients receiving radiotherapy and therefore no conclusion could be drawn on the impact of this intervention. Of note, none of the studies had investigated intensive, individualized dietary counseling. It has previously been reported that undertaking supportive care research in lung cancer patients poses challenges including low recruitment and high attrition which may explain the paucity of studies in this area. ${ }^{63}$ A recent pilot randomized trial has established the feasibility of investigating intensive, individualized dietary counseling in lung cancer patients receiving radiotherapy paving the way for future larger trials to determine the efficacy of this intervention in lung cancer patients. The pilot randomized trial demonstrated clinically important differences favoring the intervention for weight, fat-free mass, physical wellbeing, and functional wellbeing, however, these results require confirmation in a larger sample. ${ }^{64}$ There remains limited evidence regarding the efficacy of dietary counseling in lung cancer patients, however recent studies show promise and scope for further well-designed research in this area.

\section{Omega-3 fatty acids}

Patients with advanced lung cancer are reported to have a relatively high prevalence of cancer cachexia which is generally believed to be resistant to traditional forms of nutrition intervention such as dietary counseling. ${ }^{65,66}$ Therefore, nutrition intervention research in lung cancer patients has tended to focus on the use of novel agents such as omega-3 fatty acids as a treatment for cancer cachexia. ${ }^{67-69}$ A 2013 systematic review of the effect of omega-3 fatty acids on clinical outcomes in patients with cancer found mixed results. ${ }^{70}$ The review showed omega-3 fatty acids to be a safe intervention with a positive effect on QoL and physical activity. However, the effect of omega-3 fatty acids on weight, fat-free mass, and performance status was deemed inconclusive, while no benefit for nutritional intake, appetite or survival were found. There have been several studies investigating omega-3 fatty acids in lung cancer patients. In a large double blind randomized trial of 518 advanced lung and gastrointestinal cancer patients not receiving any anti-cancer treatment, no benefit on weight, fat-free mass, physical function, appetite or survival were found from supplementation with $2 \mathrm{~g}$ or $4 \mathrm{~g}$ doses of eicosapentanoic acid. ${ }^{71}$ Two smaller studies in lung cancer patients receiving active treatment have shown more positive results. In 40 lung cancer patients receiving first line chemotherapy treatment, Murphy et al, found those who were randomized to receive $2.2 \mathrm{~g}$ of fish oil maintained overall weight and maintained or gained muscle mass, measured from computed tomography images, over the course of chemotherapy compared to those who received standard care.$^{68}$ However, it should be noted the authors acknowledge the limitations of the open-label study design and the possibility the improvement in weight may have been in part due to the chemotherapy treatment itself. Another study in 40 stage III NSCLC patients receiving chemoradiation treatment showed that patients randomized to receive $2.9 \mathrm{~g}$ fish oil within an oral nutrition supplement had better weight and fat-free mass maintenance and improved protein and energy intake than those who received an isocaloric control supplement. ${ }^{69}$ While there does appear to be some benefit to omega-3 fatty acid supplementation for lung cancer patients on treatment, larger studies are required to confirm these findings.

\section{Enteral nutrition}

While there are no studies reporting specifically on the efficacy of enteral nutrition in lung cancer patients, some studies have used enteral nutrition as a component of nutrition intervention with fish oil or dietary counseling, however the use of enteral nutrition in these studies was in a limited capacity ${ }^{69,72}$ Enteral nutrition is used relatively infrequently in patients with lung cancer, with reports of as few as $12 \%$ of 
patients commencing enteral nutrition. ${ }^{17}$ In clinical practice enteral nutrition is more likely to be provided to lung cancer patients treated with curative intent chemoradiation where esophagitis can manifest as an acute toxicity severely limiting oral intake. Emerging knowledge of the factors placing lung cancer patients at higher risk of clinically significant weight loss may provide the impetus required to utilize enteral nutrition more frequently in lung cancer patients. Studies evaluating the efficacy of using enteral nutrition as a component of medical nutrition therapy in higher nutritional risk lung cancer patients are required.

\section{Multidisciplinary}

Systematic reviews indicate exercise interventions are associated with improved exercise capacity, physical strength, functional performance, and some domains of QoL in patients with NSCLC. ${ }^{73,74}$ Early studies indicate that cancer prehabilitation programs, mostly with exercise interventions prior to treatment, may improve treatment tolerance and the ability to undergo curative intent treatment. ${ }^{73,75}$ Models of care involving multi-modal nutritional rehabilitation programs, including nutritional, physical, and physiological interventions following completion of cancer treatment, have demonstrated positive effects on physical activity levels, fatigue, symptoms, weight, and nutritional status. While no studies of multi-modal nutrition and exercise interventions have been completed specifically in lung cancer patients there have been a number of reports of successful outcomes from cancer nutrition rehabilitation programs accessed by patients from a broad range of tumor groups. An uncontrolled prospective intervention study of 188 advanced cancer patients who attended a 10 - to 12 -week interdisciplinary program which provided nutritional counseling alongside an exercise program and dedicated symptom control demonstrated strong improvements in physical activity and fatigue, moderate improvements in 6-minute walk test, while $77 \%$ of patients maintained their weight. ${ }^{76}$ Within this program patients had access to a dietitian, physical therapist, occupational therapist, physician, social worker, and clinical nurse specialist. A further study of 173 cancer patients attending a similar 8-week interdisciplinary program, including access to the same health professionals, reports significant improvements in physical performance, nutrition, symptom severity, fatigue, and physical endurance. ${ }^{77}$ In light of the multidisciplinary nature of the clinical management of cancer patients, further high quality research is required to investigate the efficacy of multi-modal interventions involving nutritional, physical and psychological interventions.

\section{Conclusion}

Lung cancer patients experience a high symptom burden with many of these symptoms affecting nutritional intake and the development of malnutrition, with the potential to subsequently impact patient-related and treatment outcomes. Nutrition support and interventions are vital to optimize the wellbeing of lung cancer patients and maximize their ability to complete lengthy cancer treatments. Current research on nutrition interventions in lung cancer patients shows promise in a number of areas including intensive individualized dietary counseling, fish oil supplementation as well as multi-modal interventions encompassing both nutrition and exercise. Further good quality research and large clinical trials are needed to establish effective interventions in this patient group.

\section{Disclosure}

The author reports no conflicts of interest in this work.

\section{References}

1. International Agency for Research on Cancer [homepage on the Internet]. GLOBOCAN 2012: Estimated Cancer Incidence, Mortality and Prevalence Worldwide in 2012. World Health Organization. Available from: http://globocan.iarc.fr/Pages/fact_sheets_population. aspx. Accessed December 11, 2015.

2. American Cancer Society. Lung Cancer (Non-Small Cell). Atlanta: American Cancer Society; 2010. Available from: http://www.cancer. org/acs/groups/cid/documents/webcontent/003115-pdf.pdf. Accessed December 13, 2015.

3. American Cancer Society. Lung Cancer (Small Cell). Atlanta: American Cancer Society; 2010. Available from: http://www.cancer. org/acs/groups/cid/documents/webcontent/003116-pdf.pdf. Accessed December 13, 2015.

4. Cooley ME. Symptoms in adults with lung cancer: A systematic research review. J Pain Symptom Manage. 2000;19(2):137-153.

5. National Health and Medical Research Council [homepage on the Internet]. Clinical Practice Guidelines for the Prevention, Diagnosis and Management of Lung Cancer. Australian Cancer Network; 2004 Available from: https://www.nhmrc.gov.au/guidelines-publications/ cp97. Accessed December 13, 2015.

6. Everitt S, Krishnasamy M, Duffy M, et al. Utilising evidence to inform acute toxicity scoring for patients receiving radiation therapy for lung cancer. The Australian Journal of Cancer Nursing. 2011;12:4-9.

7. Iyer S, Roughley A, Rider A, Taylor-Stokes G. The symptom burden of non-small cell lung cancer in the USA: a real-world cross-sectional study. Support Care Cancer. 2014;22(1):181-187.

8. McCallum P. Nutrition Screening and Assessment in Oncology. In: Elliot L, Molseed L, McCallum P, editors. The Clinical Guide to Oncology Nutrition. 2nd ed. Chicago: The American Dietetic Association; 2006:44-53.

9. Segura A, Pardo J, Jara C, et al. An epidemiological evaluation of the prevalence of malnutrition in Spanish patients with locally advanced or metastatic cancer. Clin Nutr. 2005;24(5):801-814.

10. Watterson C, Fraser A, Banks M, et al. Evidence based practice guidelines for the nutritional management of malnutrition in adult patients across the continuum of care. Nutrition and Dietetics. 2009;66: S1-S34.

11. Agarwal E, Ferguson M, Banks M, et al. Nutritional status and dietary intake of acute care patients: results from the Nutrition Care Day Survey 2010. Clin Nutr. 2012;31(1):41-47. 
12. Read JA, Choy ST, Beale P, Clarke SJ. An evaluation of the prevalence of malnutrition in cancer patients attending the outpatient oncology clinic. Asia-Pacific Journal of Clinical Oncology. 2006;2(2):80-86.

13. Hébuterne X, Lemarié E, Michallet M, et al. Prevalence of malnutrition and current use of nutrition support in patients with cancer. JPEN J Parenter Enteral Nutr. 2014;38(2):196-204.

14. Mariani L, Lo Vullo S, Bozzetti F; SCRINIO Working Group. Weight loss in cancer patients: a plea for a better awareness of the issue. Support Care Cancer. 2012;20(2):301-309.

15. Unsal D, Mentes B, Akmansu M, et al. Evaluation of nutritional status in cancer patients receiving radiotherapy. Am J Clin Oncol. 2006;29(2): $183-188$.

16. Kiss N, Isenring E, Gough K, Krishnasamy M. The prevalence of weight loss during (chemo)radiotherapy treatment for lung cancer and associated patient- and treatment-related factors. Clin Nutr. 2014;33(6): 1074-1080.

17. Kiss N, Krishnasamy M, Everitt S, et al. Dosimetric factors associated with weight loss during (chemo)radiotherapy treatment for lung cancer. Eur J Clin Nutr. 2014;68(12):1309-1314.

18. Findlay M, Bauer J, Brown T, et al. Evidence based practice guidelines for the nutritional management of adult patients with head and neck cancer. Sydney, Australia: Clinical Oncological Society of Australia; 2011. Available from: wiki.cancer.org.au/australia/COSA:Head_and_ neck_cancer_nutrition_guidelines. Accessed December 13, 2015.

19. Ahmed KA, Samant S, Vieira F. Gastrostomy tubes in patients with advanced head and neck cancer. Laryngoscope. 2005;115(1):44-47.

20. Machtay M, Moughan J, Trotti A, et al. Factors associated with severe late toxicity after concurrent chemoradiation for locally advanced head and neck cancer: an RTOG analysis. J Clin Oncol. 2008;26(21): 3582-3589.

21. Gokhale AS, McLaughlin BT, Flickinger JC, et al. Clinical and dosimetric factors associated with a prolonged feeding tube requirement in patients treated with chemoradiotherapy (CRT) for head and neck cancers. Ann Oncol. 2010;21(1):145-151.

22. Gardine RL, Kokal WA, Beatty JD, et al. Predicting the need for prolonged enteral supplementation in the patient with head and neck cancer. Am J Surg. 1988;156(1):63-65.

23. Langius JA, Doornaert P, Spreenwenberg M, et al. Radiotherapy on the neck nodes predicts severe weight loss in patients with early stage laryngeal cancer. Radiother Oncol. 2010;97(1):80-85.

24. Cheng SS, Terrell JE, Bradford CR, et al. Variables associated with feeding tube placement in head and neck cancer. Arch Otolaryngol Head Neck Surg. 2006;132(6):655-661.

25. Lawson JD, Gaultney J, Saba N, et al. Percutaneous feeding tubes in patients with head and neck cancer: rethinking prophylactic placement for patients undergoing chemoradiation. Am J Otolaryngol. 2009;30(4): 244-249.

26. Nugent B, Parker MJ, McIntyre IA. Nasogastric tube feeding and percutaneous endoscopic gastrostomy tube feeding in patients with head and neck cancer. J Hum Nutr Diet. 2010;23(3):277-284.

27. Beaver ME, Matheny KE, Roberts DB, Myers JN. Predictors of weight loss during radiation therapy. Otolaryngol Head Neck Surg. 2001; 125(6):645-648

28. Bradley J, Deasy JO, Bentzen S, El-Naqa I. Dosimetric correlates for acute esophagitis in patients treated with radiotherapy for lung carcinoma. Int J Radiat Oncol Biol Phys. 2004;58(4):1106-1113.

29. Byhardt RW, Scott C, Sause WT, et al. Response, toxicity, failure patterns, and survival in five radiation therapy oncology group (RTOG) trials of sequential and/or concurrent chemotherapy and radiotherapy for locally advanced non-small-cell carcinoma of the lung. Int J Radiat Oncol Biol Phys. 1998;42(3):469-478.

30. Maguire PD, Sibley GS, Zhou SM, et al. Clinical and dosimetric predictors of radiation-induced esophageal toxicity. Int J Radiat Oncol Biol Phys. 1999;45(1):97-103.

31. Rose J, Rodrigues G, Yaremko B, Lock M, D’Souza D. Systematic review of dose-volume parameters in the prediction of esophagitis in thoracic radiotherapy. Radiother Oncol. 2009;91(3):282-287.
32. Palma DA, Senan S, Oberije C, et al. Predicting esophagitis after chemoradiation therapy for non-small cell lung cancer: an individual patient data meta-analysis. Int J Radiat Oncol Biol Phys. 2013;87(4):490-696.

33. Academy of Nutrition and Dietetics [homepage on the Internet]. Oncology Evidence-Based Nutrition Practice Guideline, 2013. Available from: http://www.andeal.org/topic. $\mathrm{cfm}$ ?menu=2819\&cat=5066. Accessed December 13, 2015.

34. Arends J, Bodoky G, Bozzetti F, et al. ESPEN guidelines on enteral nutrition: non-surgical oncology. Clin Nutr. 2006;25(2):249-259.

35. Isenring E, Zabel R, Bannister M, et al. Updated evidence-based practice guidelines for the nutritional management of patients receiving radiation therapy and/or chemotherapy. Nutrition and Dietetics. 2013;70(4): 312-324.

36. Nourissat A, Vasson MP, Merrouche Y, et al. Relationship between nutritional status and quality of life in patients with cancer. Eur $J$ Cancer. 2008;44(9):1238-1242.

37. Ovesen L, Hannibal J, Mortensen EL. The interrelationship of weight loss, dietary intake, and quality of life in ambulatory patients with cancer of the lung, breast, and ovary. Nutr Cancer. 1993;19(2):159-167.

38. Capuano G, Gentile PC, Bianciardi F, et al. Prevalence and influence of malnutrition on quality of life and performance status in patients with locally advanced head and neck cancer before treatment. Support Care Cancer. 2010;18(4):433-437.

39. Jager-Wittenaar H, Dijkstra PU, Vissink A, et al. Malnutrition and quality of life in patients treated for oral or oropharyngeal cancer. Head Neck. 2011;33(4):490-496.

40. Norman GR, Sloan JA, Wyrwich KW. Interpretation of changes in health-related quality of life: the remarkable universality of half a standard deviation. Med Care. 2003;41(5):582-592.

41. Ravasco P, Monteiro-Grillo I, Vidal PM, Camilo ME. Cancer: disease and nutrition are key determinants of patients' quality of life. Support Care Cancer. 2004;12(4):246-252.

42. Andreyev HJ, Norman AR, Oates J, Cunningham D. Why do patients with weight loss have a worse outcome when undergoing chemotherapy for gastrointestinal malignancies? Eur J Cancer. 1998;34(4):503-509.

43. Dewys WD, Begg C, Lavin PT, et al. Prognostic effect of weight loss prior to chemotherapy in cancer patients. Am J Med. 1980;69(4):491-497.

44. Ross PJ, Ashley S, Norton A, et al. Do patients with weight loss have a worse outcome when undergoing chemotherapy for lung cancers? Br J Cancer. 2004;90(10):1905-1911.

45. Arrieta O, Michel Ortega RM, Villanueva-Rodríguez G, et al. Association of nutritional status and serum albumin levels with development of toxicity in patients with advanced non-small cell lung cancer treated with paclitaxel-cisplatin chemotherapy: a prospective study. BMC Cancer. 2010;10:50.

46. Topkan E, Parlak C, Selek U. Impact of weight change during the course of concurrent chemoradiation therapy on outcomes in stage IIIB nonsmall cell lung cancer patients: retrospective analysis of 425 patients. Int J Radiat Oncol Biol Phys. 2013;87(4):697-704.

47. van den Berg MG, Rasmussen-Conrad EL, van Nispen L, van Binsbergen JJ, Merkx MA. A prospective study on malnutrition and quality of life in patients with head and neck cancer. Oral Oncol. 2008; 44(9):830-837.

48. Gupta D, Lis C, Vashi P, Lammersfeld CA. Impact of improved nutritional status on survival in ovarian cancer. Support Care Cancer. 2010;18(3):373-381.

49. Platek ME, Reid ME, Wilding GE, et al. Pretreatment nutritional status and locoregional failure of patients with head and neck cancer undergoing definitive concurrent chemoradiation therapy. Head Neck. 2011;33(11):1561-1568.

50. Capuano G, Grosso A, Gentile PC, et al. Influence of weight loss on outcomes in patients with head and neck cancer undergoing concomitant chemoradiotherapy. Head Neck. 2008;30(4):503-508.

51. Hill A, Kiss N, Hodgson B, Crowe TC, Walsh AD. Associations between nutritional status, weight loss, radiotherapy treatment toxicity and treatment outcomes in gastrointestinal cancer patients. Clin Nutr. 2011;30(1):92-98. 
52. van der Meij BS, Phernambucq EC, Fieten GM, et al. Nutrition during trimodality treatment in stage iii non-small cell lung cancer: not only important for underweight patients. J Thorac Oncol. 2011;6(9):1563-1568.

53. Jagoe RT, Goodship TH, Gibson GJ. The influence of nutritional status on complications after operations for lung cancer. Ann Thorac Surg. 2001;71(3):936-943.

54. Tewari N, Martin-Ucar AE, Black E, et al. Nutritional status affects long term survival after lobectomy for lung cancer. Lung Cancer. 2007;57(3):389-394.

55. Win T, Ritchie AJ, Wells FC, Laroche CM. The incidence and impact of low body mass index on patients with operable lung cancer. Clin Nutr. 2007;26(4):440-443.

56. Clamon G, Gardner L, Pee D, et al. The effect of intravenous hyperalimentation on the dietary intake of patients with small cell lung cancer. A randomized trial. Cancer. 1985;55(7):1572-1578.

57. Evans WK, Makuch R, Clamon GH, et al. Limited impact of tota parenteral nutrition on nutritional status during treatment for small cell lung cancer. Cancer Res. 1985;45(7):3347-3353.

58. Valdivieso M, Frankmann C, Murphy WK, et al. Long-term effects of intravenous hyperalimentation administered during intensive chemotherapy for small cell bronchogenic carcinoma. Cancer. 1987;59(2): 362-369.

59. McGeer AJ, Detsky AS, O'Rourke K. Parenteral nutrition in cancer patients undergoing chemotherapy: a meta-analysis. Nutrition. 1990;6(3):233-240.

60. Bozzetti F, Arends J, Lundholm K, et al. ESPEN Guidelines on Parenteral Nutrition: non-surgical oncology. Clin Nutr. 2009;28(4):445-454.

61. No authors listed. Bioelectrical impedance analysis in body composition measurement: National Institutes of Health Technology Assessment Conference Statement. Am J Clin Nutr. 1996;64(3 Suppl): 524S-532S.

62. Kiss NK, Krishnasamy M, Isenring EA. The effect of nutrition intervention in lung cancer patients undergoing chemotherapy and/or radiotherapy: a systematic review. Nutr Cancer. 2014;66(1):47-56.

63. Schofield P, Ugalde A, Carey M, et al. Lung cancer: challenges and solutions for supportive care intervention research. Palliat Support Care. 2008;6(3):281-287.

64. Kiss N, Isenring E, Gough K, et al. Early and intensive dietary counselling in lung cancer patients receiving (chemo)radiotherapy - a pilot randomized controlled trial. Supportive Care in Cancer. 2014; 22(1 Suppl):S116.

65. Fearon K, Strasser F, Anker SD, et al. Definition and classification of cancer cachexia: an international consensus. Lancet Oncol. 2011;12(5): 489-495.
66. Van der Meij BS, Schoonbeek CP, Smit E, et al. Pre-cachexia and cachexia at diagnosis of stage III non-small cell lung carcinoma: an exploratory study comparing two consensus-based frameworks. $\mathrm{Br} J$ Nutr. 2013;109(12):2231-2239.

67. Jatoi A, Ritter HL, Dueck A, et al. A placebo-controlled, double-blind trial of infliximab for cancer-associated weight loss in elderly and/or poor performance non-small cell lung cancer patients (N01C9). Lung Cancer. 2010;68(2):234-239.

68. Murphy RA, Mourtzakis M, Chu QS, et al. Nutritional intervention with fish oil provides a benefit over standard of care for weight and skeletal muscle mass in patients with nonsmall cell lung cancer receiving chemotherapy. Cancer. 2011;117(8):1775-1782.

69. van der Meij BS, Langius JA, Smit EF, et al. Oral nutritional supplements containing (n-3) polyunsaturated fatty acids affect the nutritional status of patients with stage iii non-small cell lung cancer during multimodality treatment. $J$ Nutr. 2010;140(10):1774-1780.

70. Van der Meij BS, Bauer J, Isenring E, et al. The effects of supplementation of $n-3$ polyunsaturated fatty acids on clinical outcome parameters in patients with cancer: a systematic review. $O A$ Epidemiology. 2013;1(1):2.

71. Fearon KC, Barber MD, Moses AG, et al. Double-blind, placebocontrolled, randomized study of eicosapentaenoic acid diester in patients with cancer cachexia. J Clin Oncol. 2006;24(21):3401-3407.

72. Evans WK, Nixon DW, Daly JM, et al. A randomized study of oral nutrition support versus ad lib nutritional intake during chemotherapy for advanced colorectal and non-small lung cancer. J Clin Oncol. 1987;5(1):113-124

73. Granger CL, McDonald CF, Irving L, et al. Low physical activity levels and functional decline in individuals with lung cancer. Lung Cancer. 2014;83(2):292-299.

74. Payne C, Larkin P, McIlfatrick S, Dunwoody L, Gracey JH. Exercise and nutrition interventions in advanced lung cancer: a systematic review. Curr Oncol. 2013;20(4):e321-e337.

75. Silver JK, Bairna J. Cancer prehabilitation: an opportunity to decrease treatment-related morbidity, increase cancer treatment options, and improve physical and psychological health outcomes. Am J Phys Med Rehabil. 2013;92(8):715-727.

76. Gagnon B, Murphy J, Eades M, et al. A prospective evaluation of an interdisciplinary nutrition-rehabilitation program for patients with advanced cancer. Curr Oncol. 2013;20(6):310-318.

77. Chasen MR, Feldstain A, Gravelle D, Macdonald N, Pereira J. An interprofessional palliative care oncology rehabilitation program: effects on function and predictors of program completion. Curr Oncol. 2013;20(6):301-309.
Lung Cancer: Targets and Therapy

\section{Publish your work in this journal}

Lung Cancer: Targets and Therapy is an international, peer-reviewed, open access journal focusing on lung cancer research, identification of therapeutic targets and the optimal use of preventative and integrated treatment interventions to achieve improved outcomes, enhanced survival and quality of life for the cancer patient. Specific topics covered in the journa include: Epideyiology, detection and sci

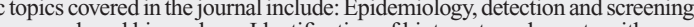
Cellular research and biomarkers; Identification of biotargets and agents with nove

\section{Dovepress}

mechanisms of action; Optimal clinical use of existing anticancer agents, including combination therapies; Radiation and surgery; Palliative care; Patient adherence, quality of life, satisfaction; Health economic evaluations. The manuscript management system is completely online and includes a very quick and fair peer-review mystem. Visit http://www.dovepress.com/testimonials php to read real quotes system. Visit http://www.dovepress.com/testimonials.php to read real quotes from
published authors. 